\title{
Induced $\gamma$-Band Activity during the Delay of a Visual Short-Term Memory Task in Humans
}

\author{
Catherine Tallon-Baudry, Olivier Bertrand, Franck Peronnet, and Jacques Pernier \\ Mental Processes and Brain Activation Laboratory, Institut National de la Santé et de la Recherche Médicale u280, \\ F-69003 Lyon, France
}

\begin{abstract}
It has been hypothesized that visual objects could be represented in the brain by a distributed cell assembly synchronized on an oscillatory mode in the $\gamma$-band $(20-80 \mathrm{~Hz})$. If this hypothesis is correct, then oscillatory $\gamma$-band activity should appear in any task requiring the activation of an object representation, and in particular when an object representation is held active in short-term memory: sustained $\gamma$-band activity is thus expected during the delay of a delayed-matching-to-sample task. EEG was recorded while subjects performed such a task. Induced (e.g., appearing with a jitter in latency from one trial to the next) $\gamma$-band activity was observed during the delay. In a control task, in which no memorization was required, this activity disappeared. Furthermore, this $\gamma$-band activity during the rehearsal of the first stimulus representation in short-term memory
\end{abstract}

How is a particular visual object represented in the brain? It has been proposed that the specific combination of attributes corresponding to one object could be coded by an assembly of neurons distributed in different functional areas, the distinctive sign of neurons belonging to the same assembly being the synchronization of their discharge on an oscillatory mode (Milner, 1974; von der Malsburg and Schneider, 1986; Singer and Gray, 1995).

Epochs of synchronization on an oscillatory mode in the $\gamma$-band $(20-80 \mathrm{~Hz})$ have been observed in various species and neural structures (for review, see Singer and Gray, 1995; Engel et al., 1997). Moreover, in support of the above hypothesis, evidence for enhanced $\gamma$-band synchronization in response to a visually coherent object has been obtained in anesthetized (Eckhorn et al., 1988; Gray et al., 1989; Engel et al., 1991; Freiwald et al., 1995; Brosch et al., 1997) and awake (Gray and Di Prisco, 1997) cats and awake monkeys (Kreiter and Singer, 1992, 1996), as well as in EEGs in humans (Lutzenberger et al., 1995; Müller et al., 1996, 1997; Tallon-Baudry et al., 1996).

Oscillatory synchronization in the $\gamma$-band thus could underlie the feature binding process. Another experiment in humans suggests that an oscillatory assembly is also activated when the internal representation of an object is needed (Tallon-Baudry et al., 1997): when subjects were required to find an hidden object in a picture (e.g., they had to activate the representation of the object searched for), enhanced $\gamma$-band activity was observed. Altogether, these results suggest that the neural correlate of the

\footnotetext{
Received Nov. 25, 1997; revised March 10, 1998; accepted March 13, 1998.

This work was supported by grants from the Human Frontier Science Program and the Rhône-Alpes region. We thank J. F. Echallier and P. E. Aguerra for helpful assistance.

Correspondence should be addressed to Catherine Tallon-Baudry, INSERM U280, 151 cours Albert Thomas, F-69003 Lyon, France.

Copyright (C) 1998 Society for Neuroscience $0270-6474 / 98 / 184244-11 \$ 05.00 / 0$
}

peaked at both occipitotemporal and frontal electrodes. This topography fits with the idea of a synchronized cortical network centered on prefrontal and ventral visual areas. Activities in the $\alpha$ band, in the 15-20 Hz band, and in the averaged evoked potential were also analyzed. The $\gamma$-band activity during the delay can be distinguished from all of these other components of the response, on the basis of either its variations or its topography. It thus seems to be a specific functional component of the response that could correspond to the rehearsal of an object representation in short-term memory.

Key words: $\gamma$-band; $40 \mathrm{~Hz}$; oscillations; cell assembly; visual short-term memory; delayed-matching-to-sample task; vision; human; EEG activation of a visual object representation is the oscillatory synchronization of an assembly, no matter whether the activation of this representation is triggered by an external input (or bottom-up process), as in feature binding, or induced by an internal event (or top-down process), as in the visual search task described above.

If the hypothesis of a correspondence between the activation of an object representation and the oscillatory synchronization of a neural assembly is correct, then induced $\gamma$-band activity should be elicited in any task requiring the activation of an object representation. The experiment presented here was designed to test whether such an oscillatory activity could be detected when an object representation is held active in short-term memory. Thirteen subjects performed a delayed-matching-to-sample task (see Fig. $1 A$ ). During the delay, subjects had to hold the representation of the first stimulus S1 in memory, and sustained $\gamma$-band activity is expected. A control task was designed (dimming condition; see Fig. $1 B$ ) in which $\mathrm{S} 1$ does not have to be memorized.

Finally, it should be emphasized that in all the studies quoted above, the functionally relevant epochs of oscillatory synchronization are not strictly triggered by stimulus onset; rather, they appear with a jitter in latency from one trial to the next. Our analysis will thus focus on so called "induced" or "nonphaselocked to stimulus onset" activities.

\section{MATERIALS AND METHODS}

Subjects. Thirteen right-handed subjects (five females, mean age 24 years) gave their informed and written consent to participate in the study. All of the subjects had normal or corrected to normal vision.

Procedure. The experiment was divided into two conditions: a memory condition and a dimming condition (Fig. 1). Before the recordings, subjects were instructed on which task they were to perform. The order in which the conditions were presented was counterbalanced between subjects. The shapes used were smooth, without any sharp angle, to avoid 


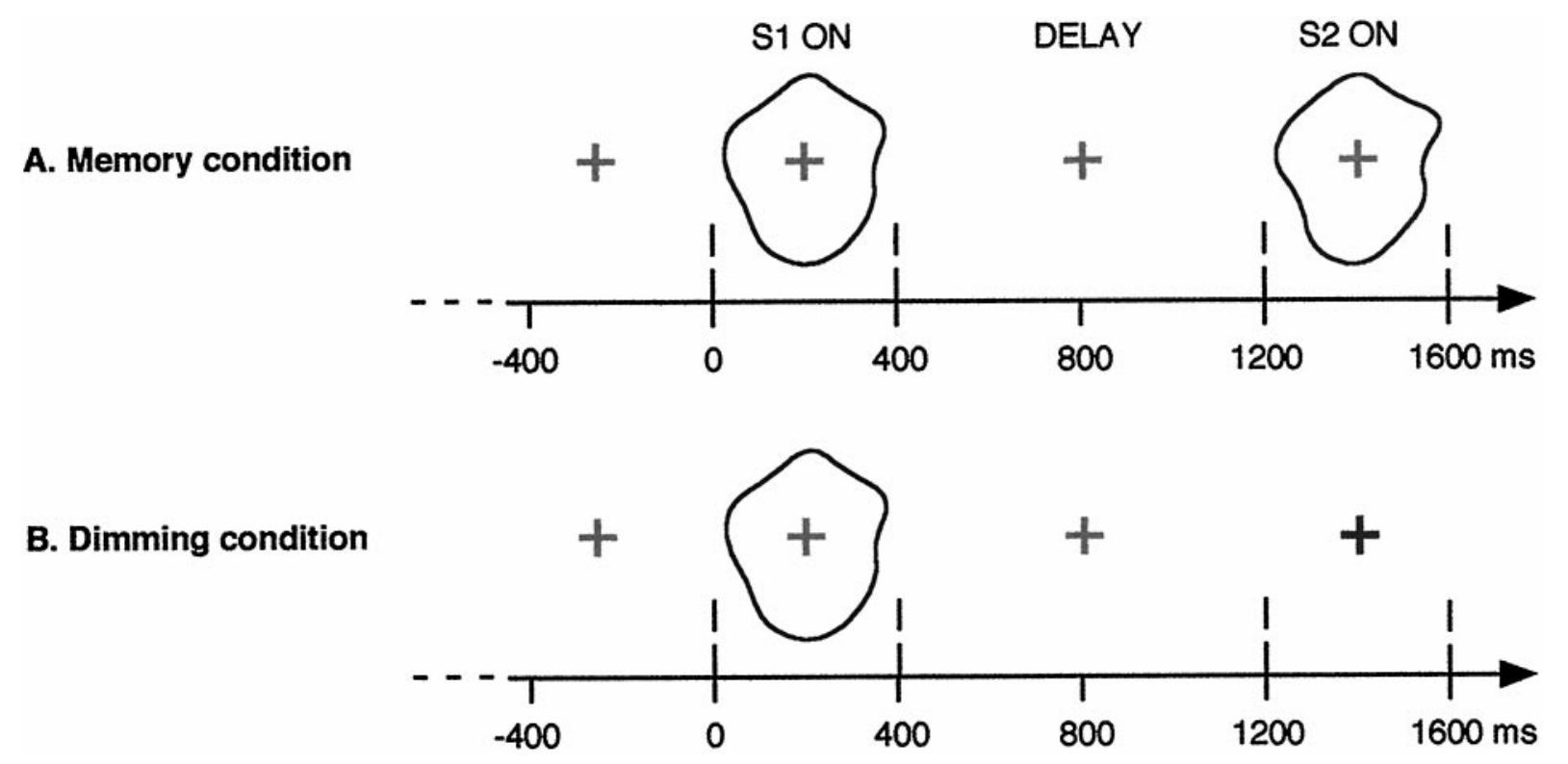

Figure 1. Experimental design. In the memory condition, two stimuli, S1 and S2, were presented for $400 \mathrm{msec}$ separated by a $800 \mathrm{msec}$ delay. Subjects were to detect matching S2 (20\% of the trials). In the dimming condition, no second stimulus appeared. Instead, the fixation cross could either dim (80\% of the trials) or remain the same (20\%), in which case subjects had to respond. In this control condition, S1 does not have to be memorized and acts only as a warning stimulus. These two conditions were presented in two successive recording sessions. We expected to find induced $\gamma$-band activity reflecting S1 representation rehearsal during the delay in the memory condition but not in the dimming condition.

any explicit spatial description of the stimulus; rather, we hoped the subjects would hold active a "photographic" representation of S1 during the delay. Stimuli were presented in black on a light gray background on a video monitor (refresh rate $106 \mathrm{~Hz}$ ). They were positioned within a disk with an inner radius of $0.88^{\circ}$ and an outer radius of $1.23^{\circ}$, at a viewing distance of $1.5 \mathrm{~m}$. In the memory condition, one trial consisted of (Fig. 1A) (1) red fixation cross for $800 \mathrm{msec}$, (2) S1 presentation for $400 \mathrm{msec}$, (3) a blank screen where only the red fixation cross remained for 800 msec, and (4) S2 presentation for $400 \mathrm{msec}$. S2 could be either different (no-go trial) or identical (go trial) to S1. In the dimming condition, one trial consisted of (1) red fixation cross for $800 \mathrm{msec}$, (2) S1 presentation for $400 \mathrm{msec}$, (3) red fixation cross for $800 \mathrm{msec}$, and (4) fixation cross $(400 \mathrm{msec})$ of a dimmed red (no-go trials) or the same red (go trials). In both conditions, the intertrial interval was randomized between 2 and 3 sec. The proportion of go trials was $20 \%$, with no more than two consecutive go trials. The difficulty of the task was adjusted to the subject's performance (see below). Subjects were instructed to press a mousekey with the right finger on go trials and to answer accurately rather than fast. They were also instructed to blink only during intertrial intervals.

Stimuli construction. Stimuli were strictly parametrized by 12 anchor points of polar coordinates $\left(r_{\mathrm{i}}, \theta_{\mathrm{i}}\right)$, with $\theta_{\mathrm{i}}=2 \pi / 12(i-1)$ and $r_{\mathrm{i}}$ being randomly chosen at each trial between $r_{\min }$ and $r_{\text {max }}$, corresponding to visual angles of $0.88^{\circ}$ and $1.23^{\circ}$, respectively. The interpolation function between four successive points $\left(\mathrm{r}_{1}, \theta_{1}\right) . .\left(\mathrm{r}_{4}, \theta_{4}\right)$ is given by Lagrange's polynomial:

$$
r(\theta)=\sum_{\mathrm{i}} r_{\mathrm{i}} \frac{\prod_{\mathrm{j} \neq \mathrm{i}}(\theta-\theta j)}{\prod_{\mathrm{j} \neq \mathrm{i}}(\theta i-\theta j)},
$$

where $i$ and $j$ vary between 1 and 4 . Only the inner segment, between $\left(\mathrm{r}_{2}, \theta_{2}\right)$ and $\left(\mathrm{r}_{3}, \theta_{3}\right)$, is drawn. The same procedure is applied until the 11 segments of the curve are drawn.

Adjustment of the difficulty of the task to the subject's performance. When $\mathrm{S} 2$ does not match $\mathrm{S} 1$, it is derived from $\mathrm{S} 1$ by modulating the radii of the 12 anchor points: $r_{\mathrm{i}}(\mathrm{S} 2)=r_{\mathrm{i}}(\mathrm{S} 1) \times(1 \pm$ coeff $)$. The sign of the modulation (increase or decrease $r_{\mathrm{i}}$ ) is chosen randomly and independently for each anchor point. The value of coeff is set at $12 \%$ at the beginning of a block of recording and constantly modified according to the subject's performance computed on the last 20 trials. If this moving average performance falls below $90 \%$, coeff is increased by $1 \%$, and the task becomes easier. On the contrary if the performance is above $90 \%$, coeff is decreased by $1 \%$, and the task becomes more difficult. The upper and lower limit values of coeff were set at $20 \%$ and $4 \%$, respectively.

In the dimming task, no second shape appears, but the intensity of the red fixation cross may decrease. The difficulty of this task is also modulated according to the subject's performance. When the moving average performance falls below $90 \%$, the intensity decrement of the screen red channel is increased by one, and the task becomes easier; if the value of the intensity decrement is decreased by one, the task becomes more difficult.

Recordings. EEG was recorded continuously at a sampling rate of 1000 $\mathrm{Hz}(0.1-320 \mathrm{~Hz}$ analog bandwidth) from $17 \mathrm{Ag}-\mathrm{AgCl}$ electrodes referenced to the nose. Electrode impedances were kept below $5 \mathrm{k} \Omega$. Their locations, according to the international 10-20 system, are Iz, P7, O1, $\mathrm{O} 2, \mathrm{P} 8, \mathrm{POz}, \mathrm{P} 3, \mathrm{Pz}, \mathrm{P} 4, \mathrm{C} 3, \mathrm{Cz}, \mathrm{C} 4, \mathrm{~F} 3, \mathrm{Fz}$, and F4. Two electrodes (OM1, OM2) were placed halfway between Iz and the mastoids. Electrode placement on the head was computer-assisted (Echallier et al., 1992). Horizontal eye movements were monitored (electrode Yh), and a rejection threshold was set for each subject at one-fourth of the potential value corresponding to a saccade of $4^{\circ}$. Four blocks of $\sim 70$ trials (56 no-go and 14 go trials) each were recorded in each condition. Epochs containing artifacts (EEG $>100 \mu \mathrm{V}$ or EOG $>$ threshold) were rejected off-line.

Time-frequency (TF) transformation of the data. We were interested in the identification and characterization of oscillatory activities induced by a stimulation. Because neither latency nor frequency of these oscillatory bursts was known a priori, a method that preserves both types of information was chosen: the time-frequency (TF) representation based on a wavelet transform of the signals (Tallon-Baudry et al., 1996, 1997). The main advantage of this approach, compared with the short-term Fourier transform approach (Makeig, 1993), is that the duration of the window of analysis depends on the frequency band: the higher the central frequency, the shorter the window duration and the wider the frequency band. This method thus provides a better compromise between time and frequency resolutions (Sinkkonen et al., 1995).

Using this method, induced activities can be analyzed. So-called induced activities appear with a jitter in latency from one trial to the next; thus, they tend to disappear on the classic averaged evoked potential. When the TF energy is computed on each single trial and averaged (TF energy averaged across single trials), induced activities can be analyzed, provided their signal-to-noise ratio is high enough. The TF transformation can also be applied to the averaged evoked potential (TF energy of the evoked potential). Induced activities tend to disappear on these plots, 
A. TF energy averaged across single trials
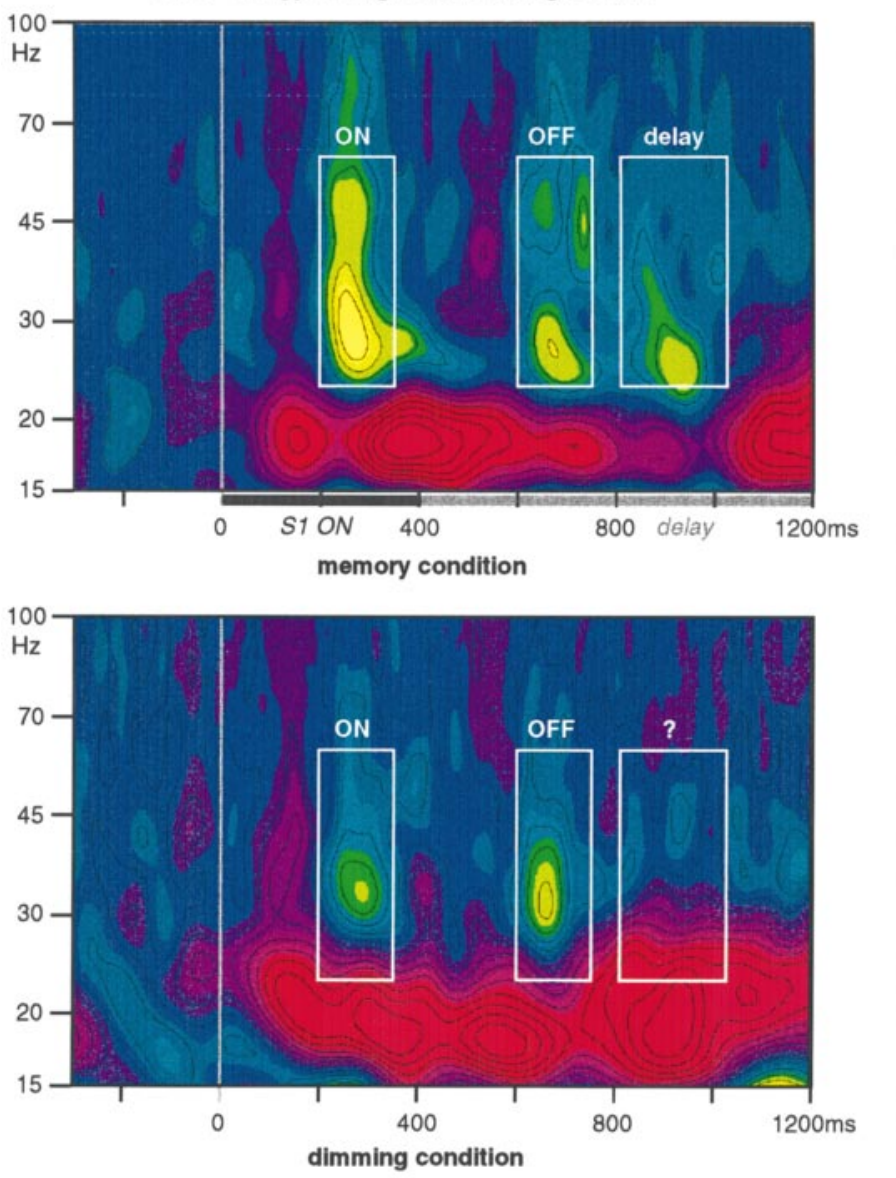

$-50$
Electrode C3

\section{B. TF energy of the averaged evoked potential}
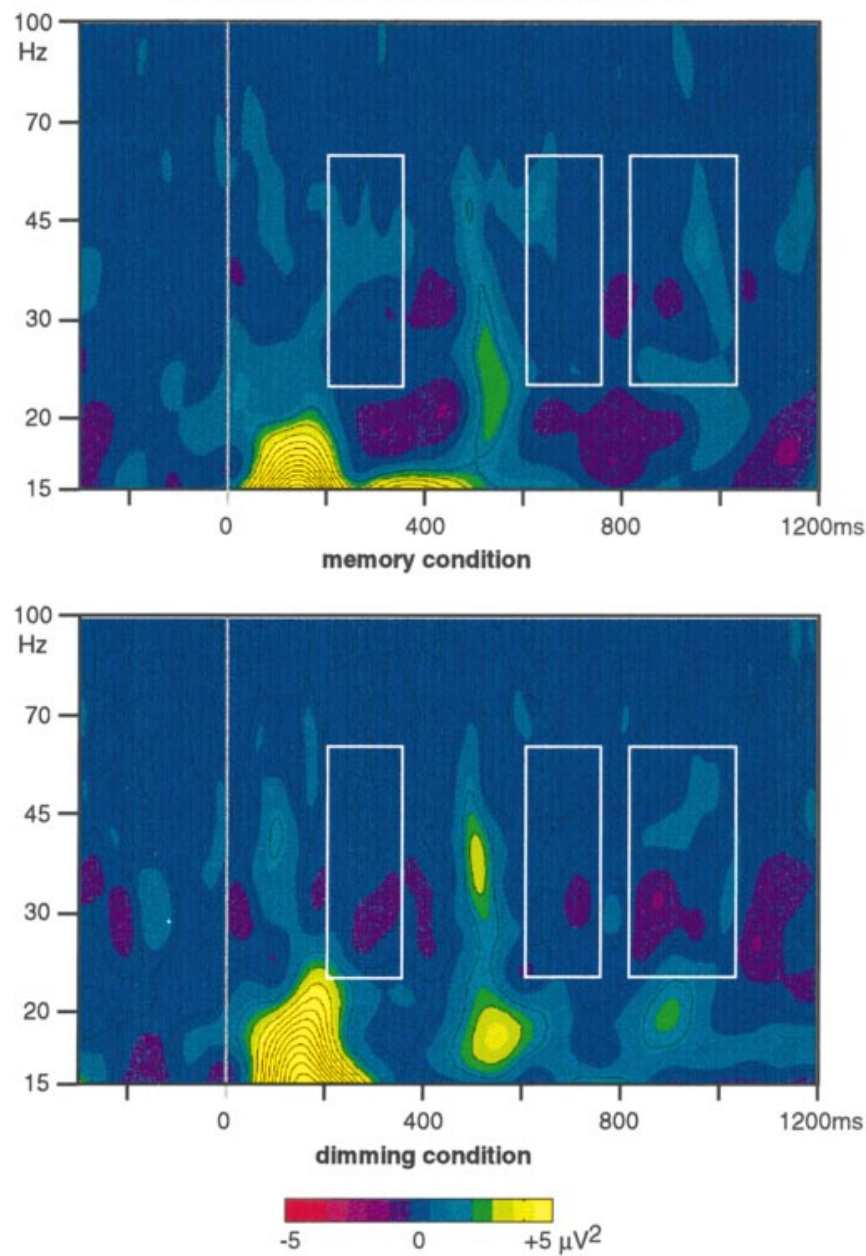

Figure 2. A, Time-frequency $(T F)$ representation of the energy averaged across single trials at electrode C3, grand average across subjects, in both conditions. Time is presented on the $x$-axis. Frequency is presented on the $y$-axis on a logarithmic scale. The energy level is coded on a color scale: yellow areas show an enhancement of energy compared with prestimulus level, and red areas show decrease. Three areas of enhanced high-frequency activity can be observed (white boxes): (1) an ON response, peaking at $\sim 280 \mathrm{msec}$ and $30 \mathrm{~Hz}$, higher in the memory than in the dimming condition; (2) an OFF response, peaking at $\sim 680 \mathrm{msec}$ (e.g., $280 \mathrm{msec}$ after $\mathrm{S} 1 \mathrm{offset}$ ), similar in both conditions; and (3) a $\gamma$-band activity during the delay, in the memory condition only. $B$, Time-frequency $(T F)$ representation of the energy of the averaged evoked potential at electrode C3, grand average across subjects, in both conditions. Only activities phase-locked to stimulus onset (e.g., appearing at a fixed latency from one trial to the next) can be observed on these representations. The three areas of enhanced high-frequency activity in $A$ thus correspond to induced activities (e.g., appearing with a latency jitter from one trial to the next).

whereas information on oscillatory bursts that are phase-locked to stimulus onset (e.g., appearing exactly at the same latency in each trial) can be obtained.

The signal was convolved with complex Morlet's wavelets $w\left(t, f_{0}\right)$ (Kronland-Martinet et al., 1987) having a Gaussian shape both in the time domain $\left(\mathrm{SD} \sigma_{\mathrm{t}}\right)$ and in the frequency domain $\left(\mathrm{SD} \sigma_{\mathrm{f}}\right)$ around its central frequency $f_{0}: w\left(t, f_{0}\right)=\mathrm{A} \cdot \exp \left(-\mathrm{t}^{2} / 2 \sigma_{\mathrm{t}}^{2}\right) \times \exp \left(2 i \pi f_{0} t\right)$, with $\sigma_{\mathrm{f}}=$ $1 / 2 \pi \sigma_{\mathrm{t}}$. Wavelets were normalized so that their total energy was 1 , the normalization factor A being equal to $\left(\sigma_{\mathrm{t}} / \pi\right)^{-1 / 2}$. A wavelet family is characterized by a constant ratio $\left(f_{0} / \sigma_{\mathrm{f}}\right)$, which should be chosen in practice greater than $\sim 5$ (Grossmann et al., 1989). The wavelet family we used was defined by $f_{0} / \sigma_{\mathrm{f}}=7$, with $f_{0}$ ranging from 8 to $100 \mathrm{~Hz}$ in $1 \mathrm{~Hz}$ steps. At $8 \mathrm{~Hz}$, this leads to a wavelet duration $\left(2 \sigma_{\mathrm{t}}\right)$ of $278 \mathrm{msec}$ and to a spectral bandwidth $\left(2 \sigma_{\mathrm{f}}\right)$ of $2.3 \mathrm{~Hz}$; at $20 \mathrm{~Hz}$, to a wavelet duration of $111.4 \mathrm{msec}$ and to a spectral bandwidth of $5.8 \mathrm{~Hz}$; and at $100 \mathrm{~Hz}$, to a duration of $22.2 \mathrm{msec}$ and a bandwidth of $28.6 \mathrm{~Hz}$. The time resolution of this method thus increases with frequency, whereas the frequency resolution decreases. The time-varying energy $E\left(t, f_{0}\right)$ of the signal in a frequency band around $f_{0}$ is the squared norm of the result of the convolution of a complex wavelet $w\left(t, f_{0}\right)$ with the signal $s(t): E\left(t, f_{0}\right)=$ $\left|w\left(t, f_{0}\right) \times s(t)\right|^{2}$. A family of wavelets will provide a TF representation of the energy of the signal. The mean TF energy of the prestimulus (between -300 and $-50 \mathrm{msec}$ ) is considered as a baseline level and subtracted from the prestimulus and poststimulus TF energy. This correction is done separately in each frequency band.

Data analysis. On average, approximately 140 correct no-go trials and 50 correct go trials were included in the analysis in each condition after artifact rejection. Because the subjects' performance was maintained at about $90 \%$, there were not enough incorrect trials to analyze them. Go and no-go trials were pooled together to improve the signal-to-noise ratio for the analysis of the responses to S1 and of the activities during the delay. Go and no-go trials were processed separately to analyze the responses to $\mathrm{S} 2$ in the memory condition.

Because the TF energy values were far from having a Gaussian distribution, the nonparametric test of Wilcoxon for matched pairs was used for all statistical analysis.

\section{RESULTS}

\section{Behavioral results}

Performance was on average $88 \%$ in both conditions. Reaction times measured on correct go trials from S1 onset were shorter in the memory $(1992 \pm 23 \mathrm{msec})$ than in the dimming condition 
A.
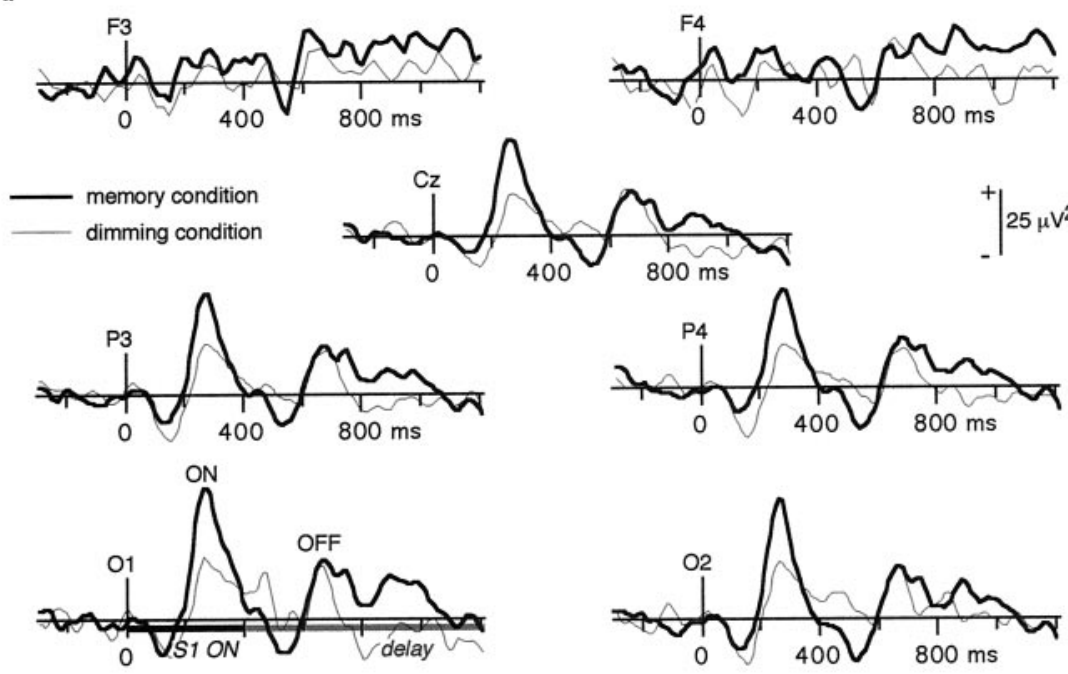

B.
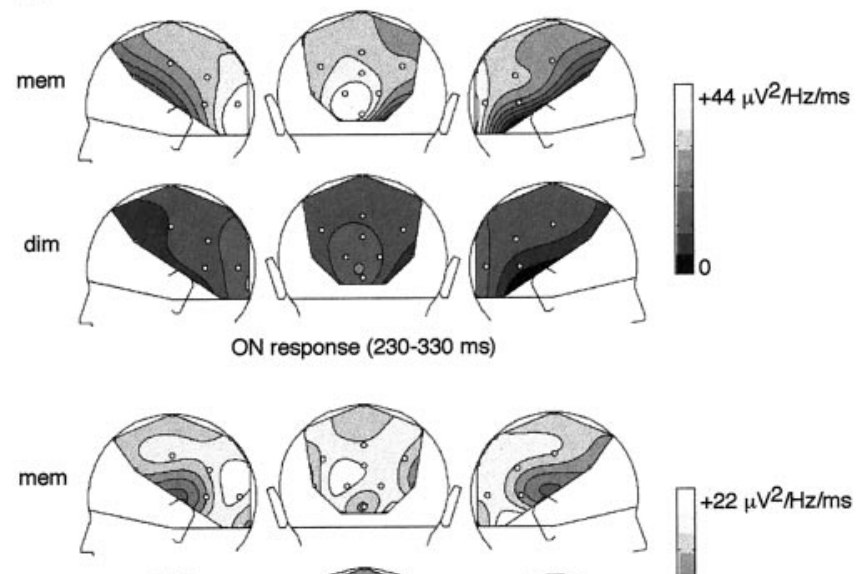

pos
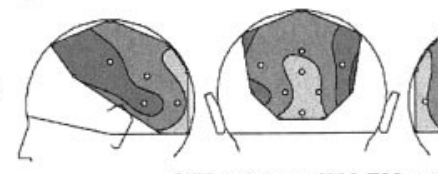

OFF response (630-730 ms)

Figure 3. A, Energy of the mean activity between 24 and $60 \mathrm{~Hz}$, grand average across subjects, in the memory (thick line) and in the dimming (thin line) conditions. A first peak of enhanced $\gamma$-band activity appears at $\sim 280 \mathrm{msec}(\mathrm{ON})$. It is significantly stronger in the memory than in the dimming condition. An OFF response can be observed at $\sim 680 \mathrm{msec}$ (e.g., 280 msec after S1 offset); it does not show any significant difference between conditions. Later on, during the delay, a sustained $\gamma$-band activity appears in the memory condition only, mainly at left posterior electrodes and bilaterally at frontal electrodes. It tends to decrease before the end of the delay. $B$, Topographical maps of the $24-60 \mathrm{~Hz}$ energy (left, back, and right views of the head) averaged between 230 and 330 msec (ON response), and between 630 and $730 \mathrm{msec}$ (OFF response). In both conditions, the ON response is maximum over occipital electrodes and decreases smoothly until the frontal sites. It is not only enhanced but also lateralized over the left hemisphere in the memory condition. The topography of the OFF response is less clear-cut; it tends to be maximum over occipital sites also. No tendency for lateralization of the OFF response could be found in any condition.
$(2049 \pm 54 \mathrm{msec})$. Although small, this difference is significant ( $p=0.039$; Wilcoxon test for matched pairs).

\section{Induced $\boldsymbol{\gamma}$-band responses}

The TF energy averaged across single trials, where oscillatory activities induced by the stimulus (e.g., appearing with a jitter in latency) can be analyzed, is presented in Figure $2 A$ for both the memory and dimming condition. Two peaks of enhanced activity around $30 \mathrm{~Hz}$ can be observed in both conditions: a first one at $\sim 280 \mathrm{msec}$ after $\mathrm{S} 1$ onset, called the ON response, and a second one at $\sim 680 \mathrm{msec}$ (e.g., $280 \mathrm{msec}$ after S1 offset) that we called an OFF-induced response. A third area of enhanced $\gamma$-band activity can also be observed during the delay in the memory condition (700-1000 msec). These three peaks of $\gamma$-band activity disappear on the TF representation of the averaged evoked potential (Fig. $2 B$, white boxes). Hence, they do correspond to induced activities. The frequency band between 24 and $60 \mathrm{~Hz}$ was chosen for further analysis of these phenomena. The choice of the lower limit of this frequency band $(24 \mathrm{~Hz})$ was made to avoid mixing these enhance- ments of $\gamma$-band energy with the decreases in energy that can be observed at lower frequencies (Fig. 2A).

\section{S1 ON and OFF $\gamma$-band responses}

The first peak of $\gamma$-band activity appears at $\sim 280 \mathrm{msec}$. It was analyzed by averaging the $24-60 \mathrm{~Hz}$ TF energy (Fig. $3 A$ ) between 230 and $330 \mathrm{msec}$ : the $\mathrm{ON}$ response is higher in the memory than in the dimming condition. This effect is significant at electrodes OM1, O1, and P3 $(p<0.04)$. Although there is a difference in energy, the $\mathrm{ON}$ response is most prominent at posterior electrodes in both conditions (Fig. $3 B$ ). Still, it is lateralized on the left in the memory condition only. When the 24-60 $\mathrm{Hz}, 230-330 \mathrm{msec}$ energy across OM1, O1, P7, and P3 was averaged and compared with the energy averaged across the corresponding electrodes over the right hemisphere (OM2, O2, $\mathrm{P} 8$, and $\mathrm{P} 4)$, a significant difference was revealed in the memory condition $(p=0.039)$ but not in the dimming condition $(p=0.39)$.

The OFF-induced $\gamma$-band response appears at $\sim 680 \mathrm{msec}$, e.g., $280 \mathrm{msec}$ after $\mathrm{S} 1$ offset (Fig. $2 A$ ). Comparing the $24-60 \mathrm{~Hz}$ 


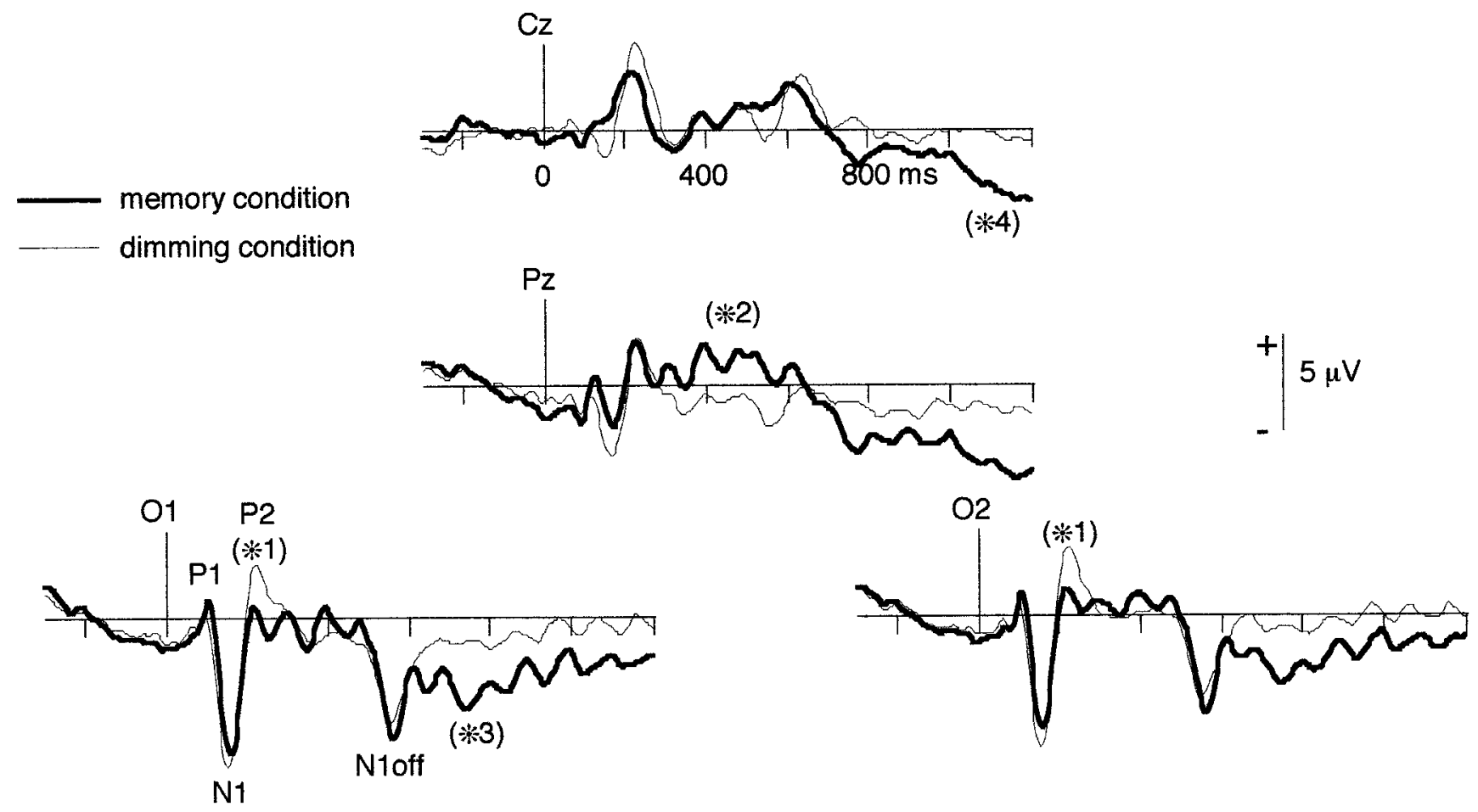

Figure 4. Filtered $(0-25 \mathrm{~Hz})$ averaged evoked potentials, grand average across subjects, in the memory (thick line) and in the dimming (thin line) conditions. The first significant difference $\left({ }^{*} 1\right)$ between the two conditions occurs at $200-240$ msec: the posterior P2 component is more pronounced in the dimming condition. Later on (300-550 msec), a sustained positivity appears at electrodes $\mathrm{POz}$ (not shown) and $\mathrm{Pz}\left({ }^{*} 2\right)$ in the memory condition. During the delay, a negativity appears at left occipitotemporal sites $\left(O 1,{ }^{*} 3\right)$ in the memory condition and tends to decrease in the end of the delay, whereas a parietocentral negativity rises $(C z, * 4)$. See also the maps of the $0-25 \mathrm{~Hz}$ evoked potential during the delay in Figure $5 B$.

energy averaged between 630 and $730 \mathrm{msec}$ at each electrode does not reveal any significant differences between conditions $(p>0.46)$. The topography of this OFF response (Fig. 3B) seems more widespread than the topography of the ON response, and no significant effect of lateralization can be found.

\section{S1 ON and OFF evoked 0-25 Hz responses}

After S1 onset, the P1 (105 msec) and N1 (155 msec) components of the averaged evoked potential filtered between 0 and $25 \mathrm{~Hz}$ can be observed in both conditions (Fig. 4). They are not affected by condition type, neither in peak latency nor in peak amplitude. The first difference in the evoked potential can be observed in the 200-240 msec time window (P2 component), where the mean amplitude is significantly enhanced in the dimming condition compared with the memory condition at electrodes OM1 $(p=$ $0.013), \mathrm{Iz}(p=0.046)$, OM2 $(p=0.033)$, and P7 ( $p=0.046)$. Later on, between 300 and $550 \mathrm{msec}$, a sustained activity is higher in the memory condition at electrodes $\mathrm{POz}$ and $\mathrm{Pz}(p<0.04)$.

An N1 OFF component appears in the evoked potential 155 msec after S1 offset, at $555 \mathrm{msec}$ (Fig. 4). It does not vary with condition type at any electrode (amplitude averaged between 500 and 600 msec; $p>0.25$ ).

\section{Induced $\boldsymbol{\gamma}$-band responses during the delay}

As depicted in Figure $3 A$, sustained $24-60 \mathrm{~Hz}$ activity is observed in the memory condition, whereas in the dimming condition, the level of $24-60 \mathrm{~Hz}$ energy is often negative (e.g., below prestimulus level). It should be noted that this sustained activity in the memory condition tends to decrease before the end of the delay. Table 1 shows the electrodes at which the difference between the two conditions during the delay is significant, on 200-msec time windows shifted by steps of 100 msec. The enhancement in the memory condition is highly significant from 750 to $1050 \mathrm{msec}$ at several electrodes; at the end of the delay (950-1150 msec), it remains significant only at electrode C3.

The topography of the $24-60 \mathrm{~Hz}$ activity during the delay is depicted in Figure $5 A$ in both conditions. In the memory condition, two regions of enhanced $\gamma$-band activity can be observed, one at left occipitotemporal electrodes and another one bilaterally at frontocentral electrodes. The occipitotemporal maximum is lateralized on the left side in the memory condition (comparison of the $24-60 \mathrm{~Hz}$ energy averaged across electrodes OM1, O1, P7, and P3 vs OM2, O2, P8, and P4; 750-950 msec time window: $p=0.003$ in the memory condition, 0.91 in the dimming condition; 850-1050 msec: $p=0.008$ in the memory condition, 0.25 in the dimming condition; $950-1150 \mathrm{msec}$ : not significant in both conditions). The frontocentral activity shows no significant preference for an hemisphere (comparison of the 24-60 Hz energy averaged across electrodes $\mathrm{C} 3$ and $\mathrm{F} 3$ vs $\mathrm{C} 4$ and $\mathrm{F} 4$ in the time windows 750-950 msec, 850-1050 msec, and 950-1150 msec: $p>0.25$ in both conditions).

\section{Evoked (0-25 Hz) responses during the delay}

The evoked potential during the delay was studied on $200 \mathrm{msec}$ time windows shifted by steps of $100 \mathrm{msec}$. Electrodes at which a significant difference between the two conditions could be found appear in Table 1. Two components are enhanced in the memory condition (Fig. 4): a sustained left-sided negativity, restricted to the posterior electrodes and more prominent at the beginning of the delay, and a parietocentral negativity that rises later on. On topographical maps (Fig. $5 B$ ), the balance between these two 
Table 1. Electrodes at which a significant effect between the two conditions can be observed, in the 24-60 Hz energy (left), in the evoked potential (middle), and in the 15-20 Hz band (right) in 200 msec time windows shifted by steps of $100 \mathrm{msec}$.

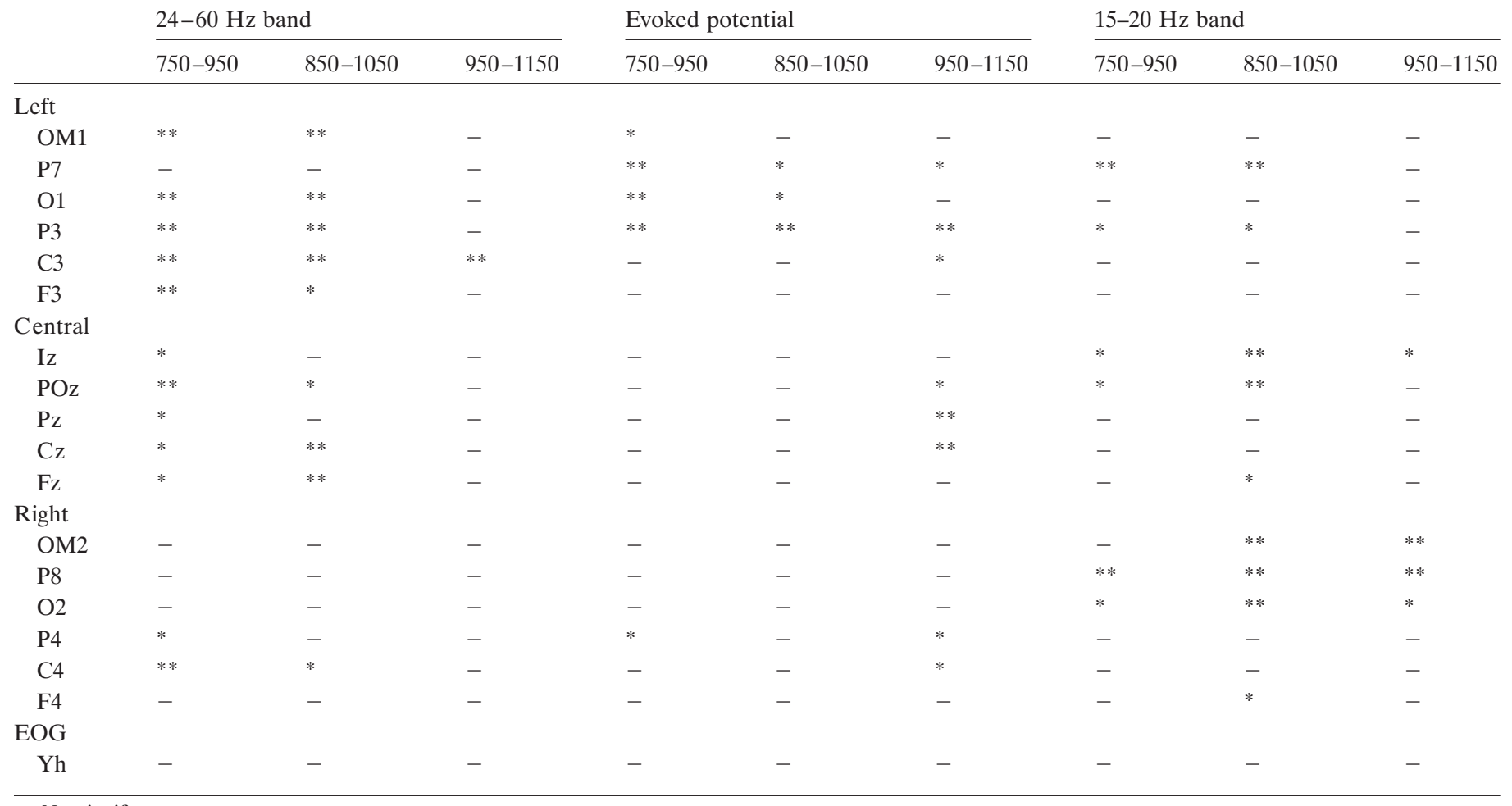

- , Nonsignificant.

$* 0.02<p<0.05$.

** $p<0.02$; nonparametric Wilcoxon test for matched pairs.

components results in a shift of the maximum of voltage from left posterior electrodes $(750 \mathrm{msec})$ to parietocentral sites (1050 msec). It should be noted that no significant difference between conditions could be found at frontal electrodes in the $0-25 \mathrm{~Hz}$ evoked potential during the delay.

\section{Induced activity in other frequency bands during the delay}

As can be seen in Figure $6 A$, in addition to the increase in the $\gamma$-band, an enhancement of the energy at lower frequencies $(15-20 \mathrm{~Hz})$ is observed in the memory condition at occipital electrodes during the delay. This peak of enhanced energy disappears on the TF representation of the evoked potential (Fig. $6 B)$; it thus corresponds to induced activity. The $15-20 \mathrm{~Hz}$ band was chosen for further analysis.

The 15-20 Hz energy during the delay was averaged on 200 msec time windows shifted by steps of $100 \mathrm{msec}$. Electrodes at which a significant difference between the two conditions could be found are shown in Table 1. Significant effects are found at both occipital and frontal sites. The occipital enhancement of the 15-20 Hz activity in the memory condition remains significant through all the delay, although the energy level in the memory condition tends to decrease in the end of the delay. The frontal enhancement in the memory condition is significant at Fz and F4 only within the $850-1050 \mathrm{msec}$ time interval. Topographical maps of this frequency band are shown in Figure $5 C$.

As opposed to the $24-60 \mathrm{~Hz}$ energy in the same latency range, the occipital component of the $15-20 \mathrm{~Hz}$ activity is not lateralized on the left side. A tendency for being lateralized on the right side in the memory condition can even be observed (Fig. 5C), although it does not reach the significance level [comparison of the averaged 15-20 Hz energy at electrodes O1 (left) and O2 (right); time window $850-1050$ msec: $p=0.13$ in the memory condition and 0.86 in the dimming condition; $950-1150$ msec: $p=0.1$ in the memory condition and 0.55 in the dimming condition]. The frontal $15-20 \mathrm{~Hz}$ activity is not lateralized (comparison of F3 vs F4; time interval $850-1050$ msec: $p=0.22$ in the memory condition and 0.80 in the dimming condition; $950-1150$ msec: $p>0.35$ in both conditions).

Finally, we studied the variations in the $\alpha$ band $(8-12 \mathrm{~Hz})$ during the delay. TF energy values averaged between 8 and $12 \mathrm{~Hz}$ and 750 and $1150 \mathrm{msec}$ did not reveal any significant difference between conditions during the delay at any electrode $(p>0.34)$. The topography of the $\alpha$ band in the 750-1150 msec time interval is shown in Figure $5 D$.

\section{Baseline level}

Up to now, the TF energy values used for statistical analysis were baseline-corrected by subtracting the averaged value of the prestimulus level between -300 and $-50 \mathrm{msec}$. For each of the frequency bands studied $(24-60,15-20$, and $8-12 \mathrm{~Hz})$, we thus examined whether there was any significant difference between conditions of the prestimulus level. Comparison of the averaged energy between -300 and -50 at each electrode did not reveal any significant difference between conditions in any frequency band $(24-60 \mathrm{~Hz}$ band: $p>0.25$; $15-20 \mathrm{~Hz}: p>0.27$; 8-12 Hz: $p>0.31)$.

\section{Responses to $\mathbf{S 2}$}

Go and no-go trials were pooled together in the analysis of the responses to $\mathrm{S} 1$ and the responses during the delay to improve the 

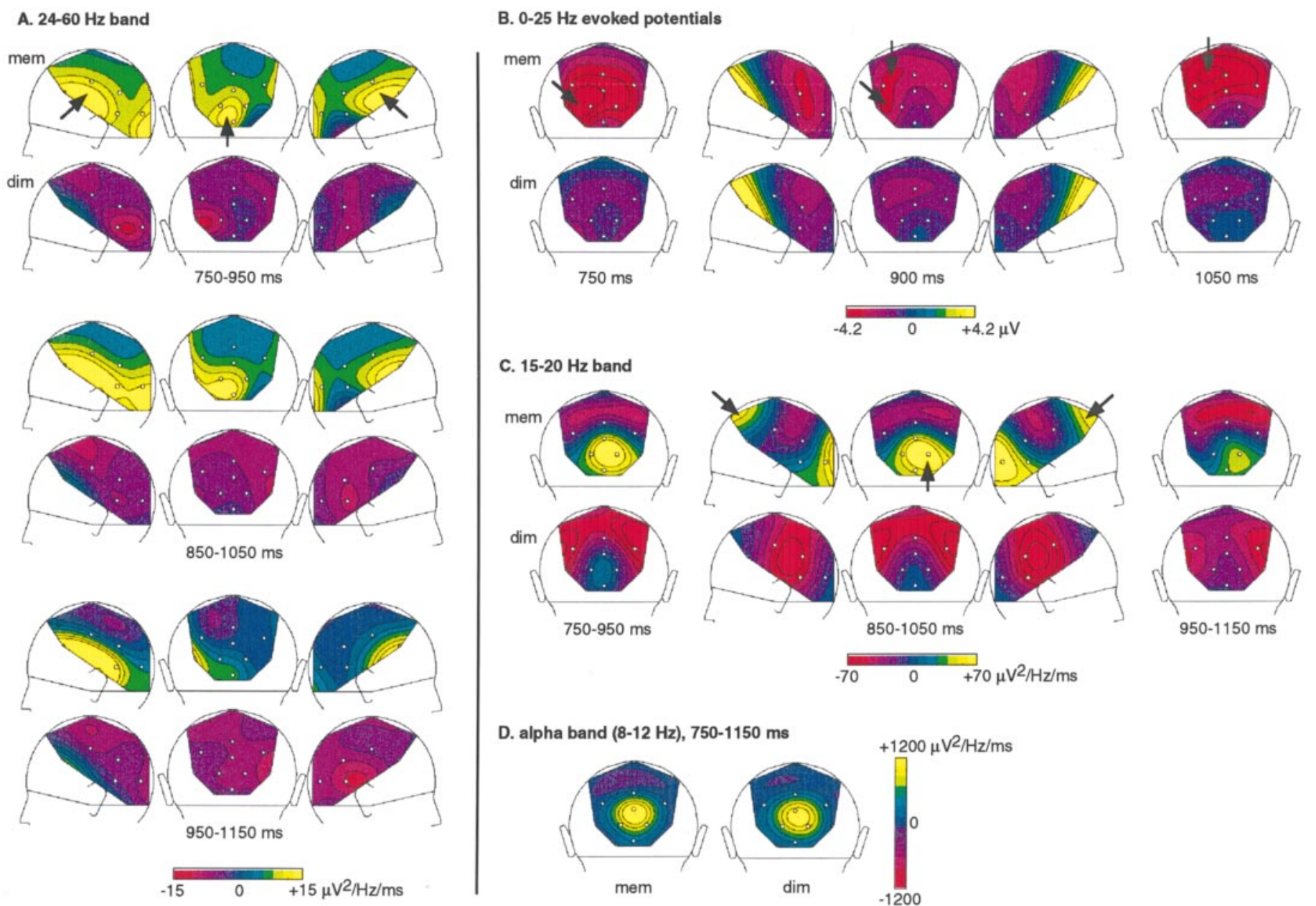

D. alpha band $(8-12 \mathrm{~Hz}), 750-1150 \mathrm{~ms}$
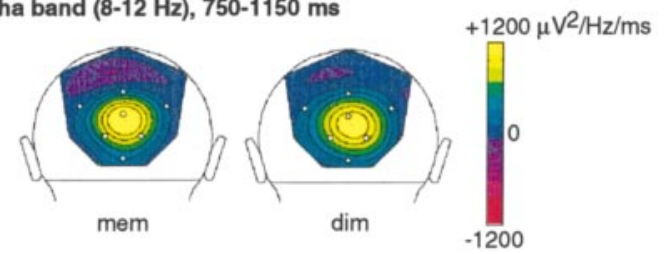

Figure 5. Summary of the activities observed during the delay. $A, \gamma$-band $(24-60 \mathrm{~Hz})$ energy in the memory (top row) and in the dimming condition (bottom row), averaged on three overlapping 200-msec time windows (750-950, 850-1050, and 950-1150 msec). Topographical maps of left, back, and right views of the head are displayed for these three time windows. Enhanced $\gamma$-band activity appears in the memory condition at left posterior electrodes, and bilaterally at more frontal sites (arrows). Differences between conditions are more significant at the beginning of the delay (750-950 and $850-1050$ msec time windows) than in the end (950-1150 msec). B. Topographical maps of the evoked potential in both conditions, at three latencies (700, 900 , and $1050 \mathrm{msec}$ ). Two negativities with different time courses and topographies can be observed in the memory condition (arrows): a left posterior negativity is prominent at the beginning of the delay and decreases in the end of the delay, whereas a parietocentral negativity rises. $C$, Energy (15-20 $\mathrm{Hz}$ ) averaged in three $200 \mathrm{msec}$ time windows in both conditions. An occipital enhancement, with a tendency for being lateralized on the right, is observed in the memory condition. Another peak of $15-20 \mathrm{~Hz}$ activity is observed in the memory condition at the midline frontal electrode. $D$, Energy in the $\alpha$-band $(8-12 \mathrm{~Hz})$, averaged between 750 and $1150 \mathrm{msec}$. No difference between the two conditions could be detected in this frequency band during the delay.

signal-to-noise ratio. To study the response to $\mathrm{S} 2$ in the memory condition, we separated the trials with matching S2 (20\%) from the trials with nonmatching S2 $(80 \%)$. The averaged evoked potentials for matching and nonmatching $\mathrm{S} 2$ at electrode $\mathrm{O} 1$ are depicted in Figure $7 A$ : matching and nonmatching S2 differ at $\sim 1410 \mathrm{msec}$, e.g., $210 \mathrm{msec}$ after S2 onset. The mean amplitude, measured in a $40 \mathrm{msec}$ time window centered at $1410 \mathrm{msec}$, differs significantly between matching and nonmatching S2 at electrode $\mathrm{O} 1$ and $\mathrm{O} 2(p=0.013)$ and $\mathrm{P} 8$ and $\mathrm{POz}(p=0.039)$. Before this latency, neither the $\mathrm{P} 1$ nor the $\mathrm{N} 1$ components vary, estimated on a $40 \mathrm{msec}$ time window centered at their peaking latency (P1: $p>$ 0.2 at all electrodes; except O1 and OM1: $p>0.1$ N $1: p>0.2$ ).

In the $\gamma$-band, a small $\mathrm{ON}$ induced response to $\mathrm{S} 2$ can be observed at $\sim 1500 \mathrm{msec}$ (Fig. $7 B$ ), e.g., $300 \mathrm{msec}$ after S2 onset and later than the difference between matching and nonmatching $\mathrm{S} 2$ in the evoked potentials. It is much smaller than the ON response to $\mathrm{S} 1$, but with a similar topography (Fig. $7 C$ ). Whether or not S2 matches, S1 does not seem to influence this small $\gamma$-band response.

\section{DISCUSSION}

\section{$\gamma$-band activity during the delay}

This experiment was designed to test the existence of induced $\gamma$-band activity when one has to hold active an object representation in short-term memory. Such an activity was indeed observed in the memory condition. It appears at left occipitotemporal electrodes and bilaterally at left and right frontal sites. In the dimming condition, where there is no need to memorize S1, no $\gamma$-band activity is found. This finding meets with the hypothesis of a representation of visual objects through the oscillatory synchronization of a distributed neural assembly.

This enhancement of $\gamma$-band activity during the delay in the memory condition appears at both occipitotemporal and frontal electrodes. The occipitotemporal component seems to be already 
A. Electrode 02
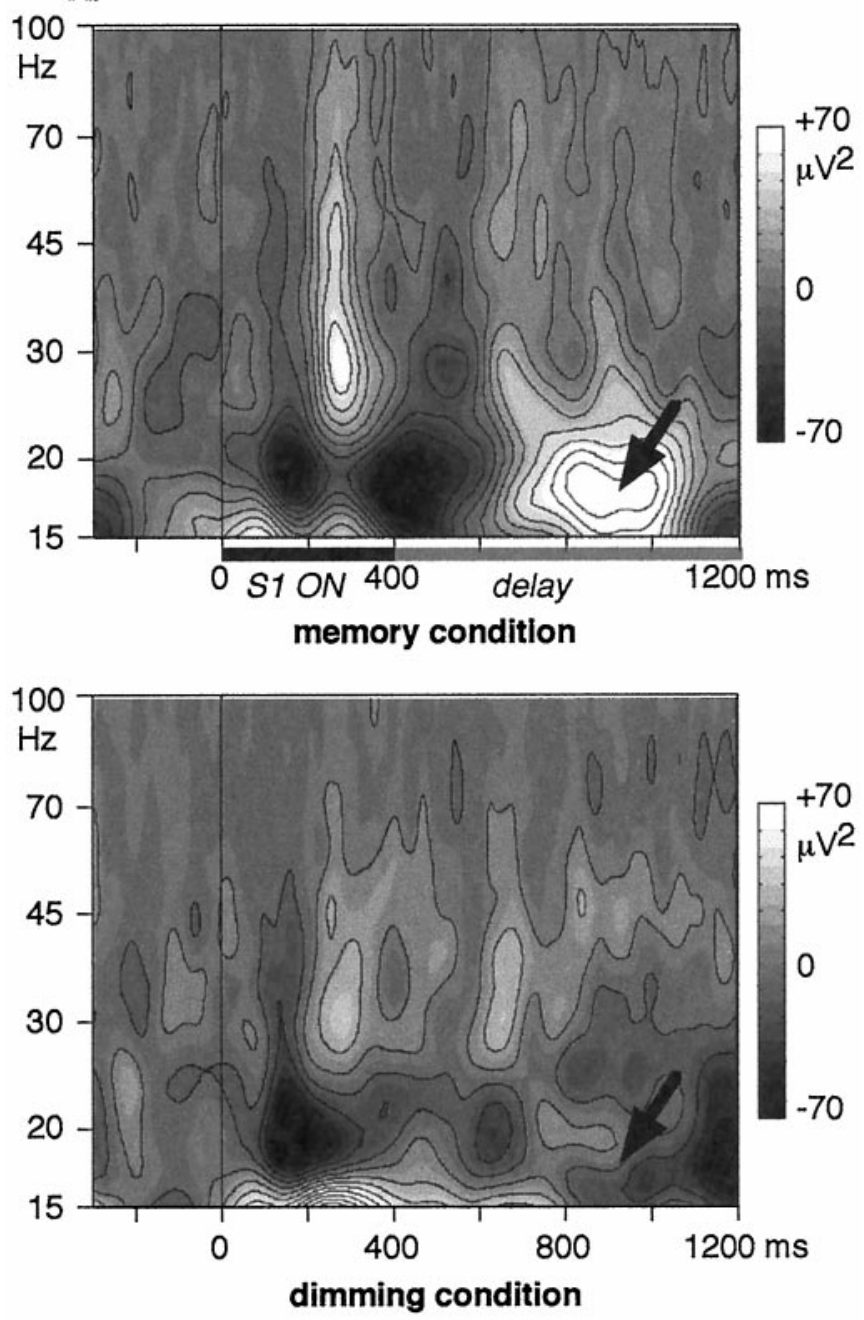

B.

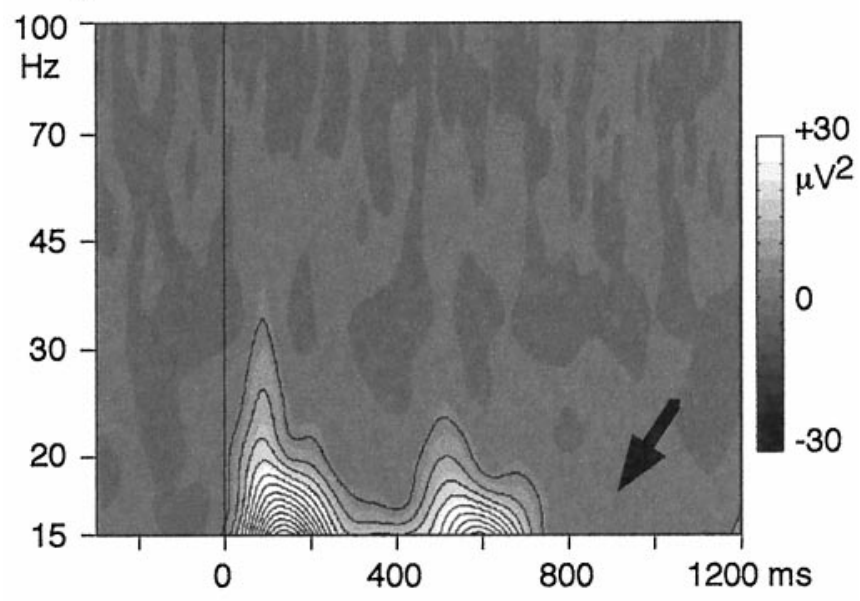

evoked potential, memory condition

Figure 6. $A$, Time-frequency energy averaged across single trials at electrode $\mathrm{O} 2$, in the memory (top) and in the dimming (bottom) conditions. Sustained $15-20 \mathrm{~Hz}$ activity is observed during the delay in the memory condition only (arrows). $B$, Time-frequency energy of the averaged evoked potential at electrode $\mathrm{O} 2$, in the memory condition. The $15-20 \mathrm{~Hz}$ energy observed during the delay disappears: it is an induced activity. present in the ON $\gamma$ response to the first stimulus. This ON occipital $\gamma$ response in previous studies (Tallon-Baudry et al., 1996, 1997) was associated with the building of an object representation. A possible interpretation of our data is that during the delay the occipital S1 representation is being rehearsed. The additional frontal $\gamma$-band activity could be necessary to maintain the occipitotemporal activity. Indeed, there may be some cortical interplay between the ventral visual areas and the prefrontal areas that have both been involved in stimulus retention in shortterm memory in animals (for review, see Goldman-Rakic, 1995; Desimone, 1996; Fuster, 1997) and humans (for review, see Ungerleider, 1995) (also see Swartz et al., 1995; Courtney et al., 1996). Although the idea of a synchronized cortical network involving prefrontal and ventral visual areas fits with current hypotheses both on short-term visual memory and on synchronized cell assembly, this interpretation goes beyond our results. Indeed, because scalp recordings do not allow one to localize directly the active neural sources, we cannot be sure that the $\gamma$-band activity appearing at left occipitotemporal and frontal electrodes is generated within the underlying cortical areas. Furthermore, we do not know whether the $\gamma$-band activities appearing at frontal and occipitotemporal electrodes are synchronized or whether they behave as two independently oscillating ensembles.

We thus interpret our data in terms of neural activity related to memory processes. We cannot rule out a possible contribution of muscle activity to our results. Nevertheless, it seems unlikely that muscle activity alone can explain our data. Indeed, it would mean that muscle activity is task-dependent (memory/dimming condition), has a different topography according to the processing stage of the stimulus in the memory condition (occipitotemporal when the stimulus is being encoded, occipitotemporal plus frontal when it is being rehearsed), and is lateralized on the left. Another argument is the frequency distribution of the induced $\gamma$-band activity compared with the frequency distribution of muscle activity. Indeed, a control experiment in one subject (Fig. 8) shows that the $\mathrm{ON}$ induced $\gamma$ response observed in the memory condition is confined to the $24-46 \mathrm{~Hz}$ band, whereas muscle activity extends up to $100 \mathrm{~Hz}$.

Because our subjects had to produce a motor response, one can also wonder whether our results are not related to $\gamma$ activity elicited by motor preparation (Pfurtscheller and Neuper, 1992; Kristeva-Feige et al., 1993; Nashmi et al., 1994; Pfurtscheller et al., 1994). This does not seem to be the case because (1) motor responses were given both in the memory and the dimming conditions, whereas we observe $\gamma$-band activity during the delay in the memory condition only; and (2) if the $\gamma$ activity we observe was related to motor preparation, one would expect it to increase until movement onset, whereas it tends to decrease even before the end of the delay.

The temporal course of the $\gamma$-band activity during the delay is indeed surprising: the energy level decreases before S2 onset. Why does not it remain high until the end of the delay? The duration of the delay was constant for all the trials, so it may be that $\mathrm{S} 2$ onset was anticipated by the subject. Such an anticipation phenomena was already described by Klimesch (1996) in the $\alpha$ band.

A number of other activities were analyzed during the delay, namely the averaged evoked potential and induced activities in the $15-20 \mathrm{~Hz}$ band and in the $\alpha$ band. Do all these activities belong to the same functional ensemble? 

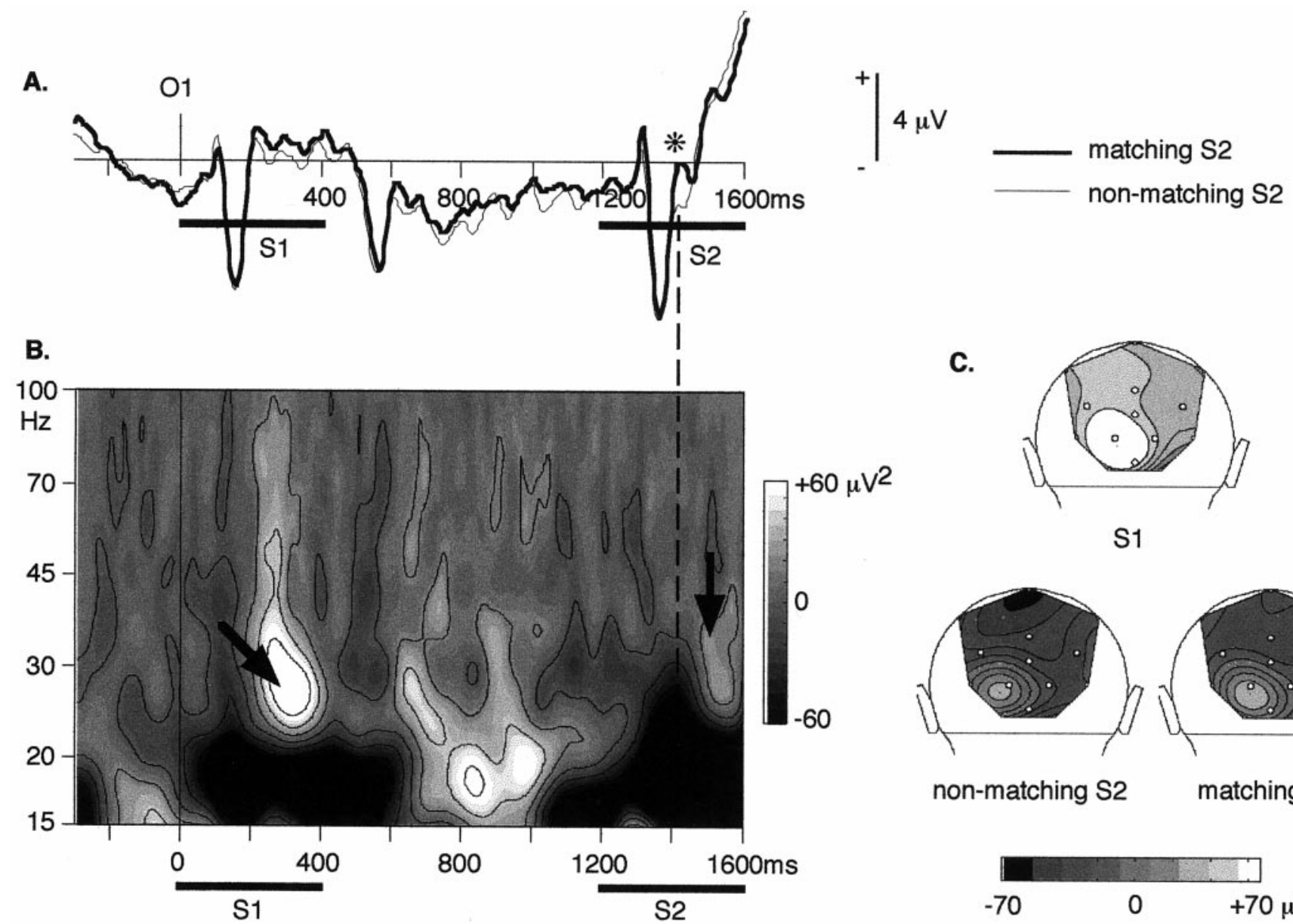

C.

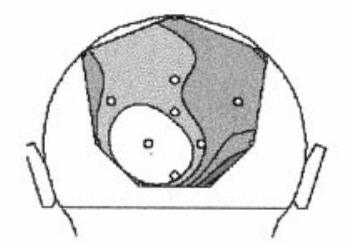

S1

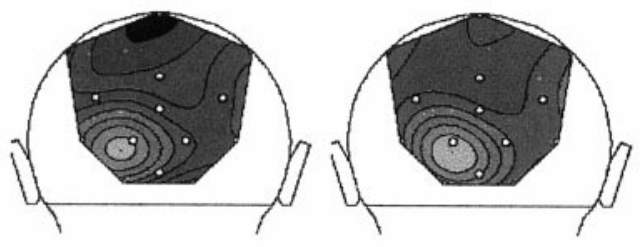

non-matching $\mathrm{S} 2$ matching $\mathrm{S} 2$

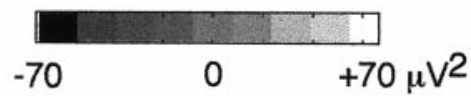

Figure 7. Responses to the matching and nonmatching $\mathrm{S} 2$ in the memory condition. $A$, Evoked $(0-25 \mathrm{~Hz})$ potentials at electrode $\mathrm{O} 1$, for matching (thin line) and nonmatching (thick line) S2. The first significant difference occurs around $1410 \mathrm{msec}(*)$, e.g., $210 \mathrm{msec}$ after S2 onset. $B$, Time-frequency representation of the energy averaged across single trials at electrode O1, in the memory condition, trials with nonmatching S2. A small $\gamma$-band response to $\mathrm{S} 2$ can be observed at $\sim 1500 \mathrm{msec}$ ( $300 \mathrm{msec}$ after S2 onset); it is much smaller than the ON response to S1. C, Topographical maps at $28 \mathrm{~Hz}$ (back views) of the ON response to S1 (top), of the ON response to nonmatching S2 (bottom left), and of the ON response to matching S2 (bottom right). In both cases (matching or nonmatching S2), the ON response to S2 is much smaller than the response to S1. Nevertheless, it shows the same left occipital maximum.

\section{Evoked potentials $(0-25 \mathrm{~Hz})$}

The $0-25 \mathrm{~Hz}$ filtered evoked potential shows two enhanced components in the memory condition: a left posterior negativity and a parietocentral negativity. It should be emphasized that no differences between conditions were detected at frontal electrodes in the evoked potential. The left occipitotemporal negativity may be related to the sustained firing of inferotemporal neurons observed in similar tasks in animal (Fuster and Jervey, 1981; Miyashita and Chang, 1988; Fuster, 1990; Miller and Desimone, 1993). It may be tightly linked to the $\gamma$-band activity appearing at the same left occipitotemporal electrodes. A possible functional role for this component is to prepare a speedy matching process between $\mathrm{S} 1$ and $\mathrm{S} 2$, because later on the evoked potentials reflect the result of this process by indicating a difference between matching and nonmatching S2. This difference between matching and nonmatching S2 in the evoked potential was already observed in other studies in the same latency range (Begleiter et al., 1993; Sugita, 1994). Furthermore, if this difference means that the comparison process between S1 and S2 is completed $210 \mathrm{msec}$ after S2 onset, it may account for the reduced $\gamma$-band response $300 \mathrm{msec}$ after S2 onset: there is no need for building a representation of $\mathrm{S} 2$ because the matching task is over.
The other component in the evoked potential during the delay is a rising parietocentral negativity. It is greater in the memory than in the dimming condition. Both the topography (parietocentral) and the time course (increases until S2 onset) of this negativity suggest that it belongs to the family of contingent negative variation waves, which have been observed repeatedly in humans in paired S1-S2 paradigms, especially when the contingency between the two stimuli is strong (for review, see Tecce and Cattanach, 1987).

\section{Activity in other frequency bands during the delay}

During the delay, an enhancement of induced activity in the $15-20 \mathrm{~Hz}$ band in the memory condition can also be observed at some electrodes. It thus shows the same functional variations with conditions as the activity in the $\gamma$-band. Furthermore, its temporal course is quite similar to the temporal course of the $\gamma$-band activity during the delay, with a tendency to decrease before S2 onset. Still, the topographies of these two activities are different: at least partially different areas would be involved in the generation of 24-60 and $15-20 \mathrm{~Hz}$ activities. The difference between the 24-60 and 15-20 Hz topographies may also partly justify the 


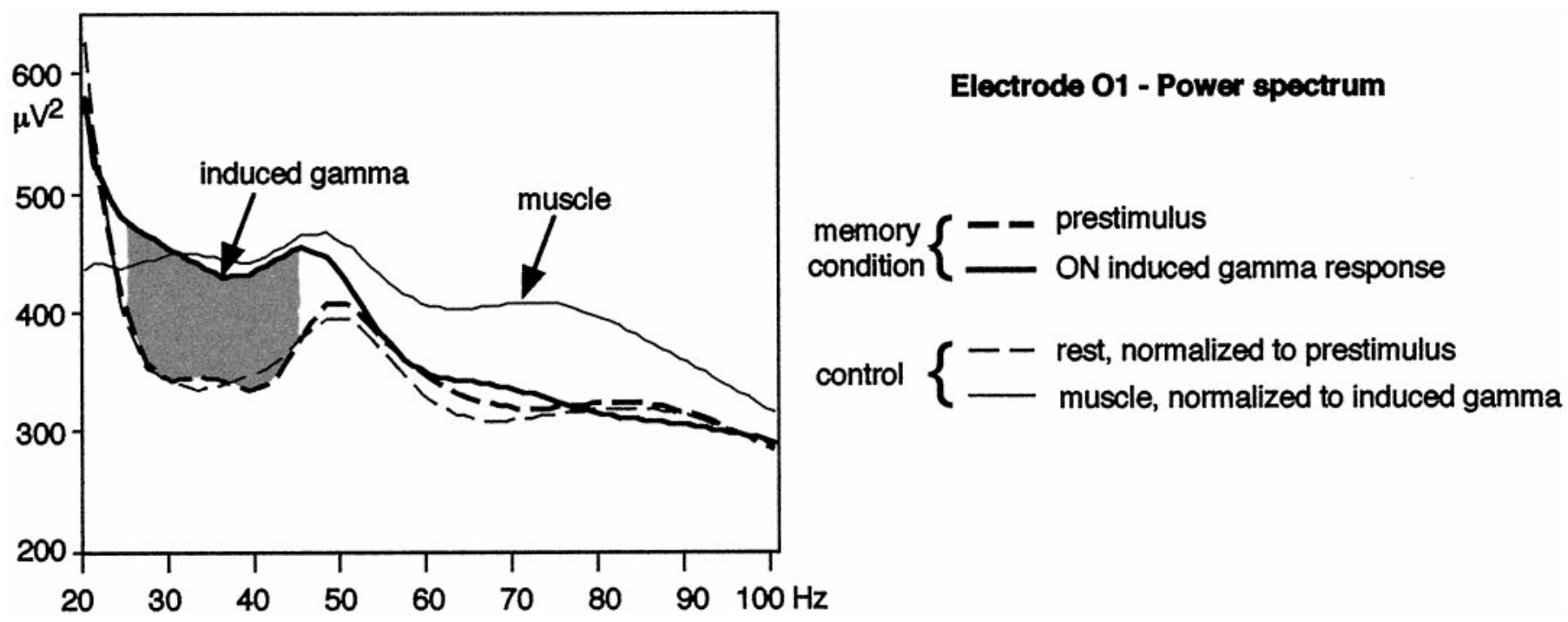

Figure 8. Power spectrum of the $\mathrm{ON}$ induced $\gamma$ response compared with muscle activity (one subject, electrode $\mathrm{O} 1$ referenced to the nose). The subject was first recorded while performing the memory task. Comparison of the spectrum of the prestimulus $(-350$ to $-50 \mathrm{msec})$ to the spectrum of the ON induced $\gamma$-band response $(270-320 \mathrm{msec}$ ) reveals a difference around $35 \mathrm{~Hz}$ (gray area), whereas above $55 \mathrm{~Hz}$, both spectra are similar. The ON induced $\gamma$ response is thus confined to a narrow frequency band. The subject was then recorded while simply fixating on the screen, both at rest and when contracting different muscles (neck, jaw, eyebrow). The power spectrum at rest was lower than during the prestimulus of the memory condition, but with a similar profile. To get rid of scaling effects, the power spectrum at rest was normalized with respect to the $24-46 \mathrm{~Hz}$ band of the power spectrum of the prestimulus. Similarly, the power spectrum of muscle activity was normalized with respect to the $24-46 \mathrm{~Hz}$ band of the ON induced response power spectrum. It clearly appears that the effect of muscle activity is not restricted to this $24-46 \mathrm{~Hz}$ band, but extends up to $100 \mathrm{~Hz}$. The same type of spectrum is observed when the different muscles (neck, jaw, eyebrow) are activated separately.

choice of these two frequency bands: they do not reflect the same phenomena.

Activity in the $\alpha$-band $(8-12 \mathrm{~Hz})$ during the delay did not show any significant difference between conditions during the delay, which seems to rule out the possibility (Jürgens et al., 1995) that either the $\gamma$-band or the $15-20 \mathrm{~Hz}$ activities are simply harmonics of $\alpha$ activity, at least in this experiment. In other studies (Gevins et al., 1997; Klimesch et al., 1997), energy in the $\alpha$-band was found to correlate with memory load. Still, both the protocols (continuous matching task or words learning and recognition) and the long time windows that were studied $(>1 \mathrm{sec})$ in these experiments are very different from what we used.

\section{Responses to S1}

Responses to $\mathrm{S} 1$ differ in the memory and in the dimming tasks. Evoked potentials show a decrease of the P2 component in the memory condition, which could be associated with feature selection processes (for review, see Anllo-Vento and Hillyard, 1996). It is followed by a positive wave that may be related to the memory encoding process. In the $\gamma$-band, the $\mathrm{ON}$ induced response appearing at $\sim 280 \mathrm{msec}$ after S1 onset is reduced in the dimming condition, where S1 probably acts only as a warning stimulus. Because our experimental protocol was designed to study the delay, during S1 presentation many behavioral parameters differ between conditions (spatial attention more focal in the dimming task, feature selective attention to shape and memory encoding in the memory task, etc.). It is thus difficult to give a precise interpretation of the responses to $\mathrm{S} 1$.

Finally, OFF responses to S1 have been observed not only in the evoked potential but also in the $\gamma$-band. To our knowledge, such a response had not been described so far in the $\gamma$-band. Its latency (280 msec after S1 offset) seems to indicate that it is indeed an induced $O F F$ response. Because it does not vary be- tween conditions in this experiment, its functional significance remains unclear.

\section{Conclusion}

Both the existence and the topography of the $\gamma$-band activity during the delay in the memory condition fit the hypothesis of an oscillatory network centered on prefrontal and visual areas that would ensure the rehearsal of the first stimulus representation in memory. This experiment does not prove definitively that this interpretation is the right one. In particular, we have not ruled out definitively a possible contribution of muscle activity to our data. In any case, oscillatory $\gamma$-band activity seems to be a specific component of the response: it can be distinguished from the averaged evoked potential and from activities in other frequency bands $(8-12,15-20 \mathrm{~Hz})$ either by its topography or by its variations with conditions. Finally, the topography of $\gamma$-band activity is modified depending on whether S1 is being encoded (left occipitotemporal) or rehearsed (left occipitotemporal plus frontal). This suggests that depending on the task to be performed, different functional areas can be recruited to participate in an oscillatory $\gamma$-band ensemble.

\section{REFERENCES}

Anllo-Vento L, Hillyard SA (1996) Selective attention to the color and direction of moving stimuli: electrophysiological correlates of hierarchical feature selection. Percept Psychophys 58:191-206.

Begleiter H, Porjesz B, Wang W (1993) A neurophysiologic correlate of visual short-term memory in humans. Electroenceph Clin Neurophysiol 87:46-53.

Brosch M, Bauer R, Eckhorn R (1997) Stimulus-dependent modulations of correlated high-frequency oscillations in cat visual cortex. Cereb Cortex 7:70-76.

Courtney SM, Ungerleider LG, Keil K, Haxby JV (1996) Object and spatial visual working memory activate separate neural systems in human cortex. Cereb Cortex 6:39-49. 
Desimone R (1996) Neural mechanisms for visual memory and their role in attention. Proc Natl Acad Sci USA 93:13494-13499.

Echallier JF, Perrin F, Pernier J (1992) Computer assisted placement of electrodes on the human head. Electroenceph Clin Neurophysiol 82:160-163.

Eckhorn R, Bauer R, Jordan W, Brosch M, Kruse W, Munk M, Reitboeck HJ (1988) Coherent oscillations: a mechanism of feature linking in the visual cortex? Biol Cybern 60:121-130.

Engel AK, König P, Singer W (1991) Direct physiological evidence for scene segmentation by temporal coding. Proc Natl Acad Sci USA 88:9136-9140.

Engel AK, Roelfsema PR, Fries P, Brecht M, Singer W (1997) Role of the temporal domain for response selection and perceptual binding. Cereb Cortex 7:571-582.

Freiwald WA, Kreiter AK, Singer W (1995) Stimulus dependent intercolumnar synchronization of single unit responses in cat area 17. NeuroReport 6:2348-2352.

Fuster JM (1990) Inferotemporal units in selective visual attention and short-term memory. J Neurophysiol 64:681-697.

Fuster JM (1997) Network memory. Trends Neurosci 20:451-459.

Fuster JM, Jervey JP (1981) Inferotemporal neurones distinguish and retain behaviorally relevant features of visual stimuli. Science 212:952-955.

Gevins A, Smith ME, Mcevoy L, Yu D (1997) High-resolution EEG mapping of cortical activation related to working memory: effects of task difficulty, type of processing, and practice. Cereb Cortex 7:374-385.

Goldman-Rakic PS (1995) Cellular basis of working memory. Neuron 14:477-485.

Gray CM, DiPrisco GV (1997) Stimulus-dependent neuronal oscillations and local synchronization in striate cortex of the alert cat. J Neurosci 17:3239-3253.

Gray CM, König P, Engel AK, Singer W (1989) Oscillatory responses in cat visual cortex exhibit inter-columnar synchronization which reflects global stimulus properties. Nature 338:334-337.

Grossmann A, Kronland-Martinet R, Morlet J (1989) Reading and understanding continuous wavelets transforms. In: Wavelets, timefrequency methods and phase space (Combes JM, Gossmann A, Tchamitchian P, eds), pp 2-20. Berlin: Springer.

Jürgens E, Rösler F, Hennighausen E, Heil M (1995) Stimulus-induced gamma oscillations: harmonics of alpha activity? NeuroReport 6:813-816.

Klimesch W (1996) Memory processes, brain oscillations and EEG synchronization. Int J Psychophysiol 24:61-100.

Klimesch W, Doppelmayr M, Schimke H, Ripper B (1997) Theta synchronization and alpha desynchronization in a memory task. Psychophysiology 34:169-176.

Kreiter AK, Singer W (1992) Oscillatory neuronal responses in the visual cortex of the awake macaque monkey. Eur J Neurosci 4:369-375.

Kreiter AK, Singer W (1996) Stimulus-dependent synchronization of neuronal responses in the visual cortex of the awake macaque monkey. J Neurosci 16:2381-2396.

Kristeva-Feige R, Feige B, Makeig S, Ross B, Elbert T (1993) Oscillatory brain activity during a motor task. NeuroReport 4:1291-1294.

Kronland-Martinet R, Morlet J, Grossmann A (1987) Analysis of sound patterns through wavelet transforms. Int J Patt Recogn Art Intell 1:273-302.

Lutzenberger W, Pulvermüller F, Elbert T, Birbaumer N (1995) Visual stimulation alters local $40 \mathrm{~Hz}$ responses in humans: an EEG study. Neurosci Lett 183:39-42.

Makeig S (1993) Auditory event-related dynamics of the EEG spectrum and effects of exposure to tones. Electroenceph Clin Neurophysiol 86:283-293.

Miller EK, Li L, Desimone R (1993) Activity of neurons in anterior inferior temporal cortex during a short-term memory task. J Neurosci 13:1460-1478.

Milner PM (1974) A model for visual shape recognition. Psychol Rev 81:521-535.

Miyashita Y, Chang HS (1988) Neuronal correlate of pictorial shortterm memory in the primate temporal cortex. Nature 331:68-70.

Müller MM, Bosch J, Elbert T, Kreiter AK, Sosa MV, Sosa PV, Rockstroh B (1996) Visually induced gamma-based responses in human electroencephalographic activity: a link to animal studies. Exp Brain Res 112:96-102.

Müller MM, Junghofer M, Elbert T, Rochstroh B (1997) Visually induced gamma-band responses to coherent and incoherent motion: a replication study. NeuroReport 8:2575-2579.

Nashmi R, Mendonça AJ, Mackay WA (1994) EEG rhythms of the sensorimotor region during hand movements. Electroenceph Clin Neurophysiol 91:456-467.

Pfurtscheller G, Neuper C (1992) Simultaneous EEG 10 Hz desynchronization and $40 \mathrm{~Hz}$ synchronization during finger movements. NeuroReport 3:1057-1060.

Pfurtscheller G, Flotzinger D, Neuper C (1994) Differentiation between finger, toe and tongue movement in man based on $40 \mathrm{~Hz}$ EEG. Electroenceph Clin Neurophysiol 90:456-460.

Singer W, Gray CM (1995) Visual feature integration and the temporal correlation hypothesis. Annu Rev Neurosci 18:555-586.

Sinkkonen J, Tiitinen H, Näätänen R (1995) Gabor filters: an informative way for analyzing event-related brain activity. J Neurosci Methods 56:99-104.

Sugita Y (1994) Electrophysiological correlates of human visual recognition memory. Neurosci Lett 178:151-154.

Swartz BE, Halgren E, Fuster JM, Simpkins F, Gee M, Mandelkern M (1995) Cortical metabolic activation in humans during a visual memory task. Cereb Cortex 5:205-214.

Tallon-Baudry C, Bertrand O, Delpuech C, Pernier J (1996) Stimulus specificity of phase-locked and non-phase-locked $40 \mathrm{~Hz}$ visual responses in human. J Neurosci 16:4240-4249.

Tallon-Baudry C, Bertrand O, Delpuech C, Pernier J (1997) Oscillatory $\gamma$-band $(30-70 \mathrm{~Hz})$ activity induced by a visual search task in humans. J Neurosci 17:722-734.

Tecce JJ, Cattanach L (1987) Contingent negative variation (CNV). In: Electroencephalography, Ed 2 (Niedermeyer E, Lopes da Silva F, eds), pp 657-679. Baltimore: Urban \& Schwarzenberg.

Ungerleider LG (1995) Functional brain imaging studies of cortical mechanisms for memory. Science 270:769-775.

von der Malsburg C, Schneider W (1986) A neural cocktail-party processor. Biol Cybern 54:29-40. 